\title{
DIE EFFEK VAN STADIGE BAROKMUSIEK OP PREMATURE BABAS
}

\author{
E AIKMAN, AGW NOLTE en DÖRFLING
}

\section{INLEIDING}

The maturing foetus belongs in utero, not in the demanding environment of a specialized care unit. Infants born before term are fragile; their ability to adapt and survive in new surroundings is limited. Although current survival rates are encouraging, morbidity among preterm infants persists and may have iatrogenic underpinnings. As a result, neonatal intensive care units are under closer scrutiny than ever, especially in terms of how they may contribute to developmental disability." (Thomas, 1989:249)

\section{DIE INTRA-UTERIENE OMGEWING}

Die intra-uteriene omgewing is ' $n$ unieke wêreld (Weibly, 1989: 96) vir die groei, ontwikkeling en beskerming van die fetus (Mills en Aikin, 1984: 34-39). Hierdie omgewing word as warm, donker en geïsoleerd beskryf. Die amnionvog beskerm die fetus teen die oorweldigende sensoriese ervarings en stressors van die ekstra uteriene omgewing (De Lue, 1976: 425).

Baie teorieë steun die mens se aangetrokkenheid tot ritme as gevolg van die ritmiese uteriene omgewing (Woodward et al., 1992: 15) en die ritme van die bloed wat deur die plasenta vloei (Collins, 1991: 24).

Die akoestiese omgewing en gehoorstimulasie waaraan die fetus blootgestel is, sluit agtergrondklanke op lae frekwensie soos kardiovaskulêre, intestinale en plasentale klanke in (Woodward et al., 1992: 15). Die fetus is ook gewoond aan die moeder se stem en die ritme daarvan (Linn et al., 1985: 408 - 409).

\section{DIE EKSTRA-UTERIENE OMGEWING}

By geboorte moet die fetus binne minute van die warm, geïsoleerde, donker omgewing by ' $n$ koue, raserige, tegnologiese, helder verligte omgewing aanpas (De Lue, 1976: 425). Die ontwikkelende fetus hoort in die uterus en nie in ' $n$ veeleisende omgewing soos 'n gespesialiseerde sorgeenheid nie (Thomas, 1989: 249).

Die neonatale intensiewesorgeenheid is ' $n$ omgewing van intensiteite, maar het ook 'n nodige en definitiewe plek in die premature baba se lewe. Die neonatale intensiewesorgeenheid voorsien in al die baba se behoeftes, maar het dikwels ' $n$ negatiewe uitwerking op die premature baba weens byvoorbeeld hoë geraaspeile, konstante hantering, pynlike intervensies en voortdurende ligte (Hansen, 1982: 18).

Die siek premature baba is aan hierdie omgewing blootgestel vir ' $n$ tydperk van 15 tot 50 dae of selfs langer (Ziporyn, 1984:292). Babas, veral dié met ' $n$ baie lae geboorte gewig, mag afwyk van die basiese ontwikkelingspatroon en mag aansienlike stres ondervind (Caine, 1991:181).

Die babas in die neonatale intensiewesorgeenheid ly dikwels aan slaapontneming en stres bring ' $n$ abnormale hoë persentasie tyd in wakker fases deur as gevolg van verpleging en geraasvlakke (Zahr en Balian, 1995:184). Die geraasvlakke in die neontale intensiewesorgeenhede is dikwels gelykstaande aan dié van spitsverkeer (Thomas, 1989:250), terwyl die lig in die neonatale intensiewesorgeenheid soortgelyk is aan direkte sonlig (Shogan en Schumann, 1993:7). 'n Premature baba het nie dieselfde georganiseerde neurologiese funksies soos ' $n$ voltydse baba nie en reageer daarom nie dieselfde as ' $n$ voltydse baba op die ekstrauteriene omgewing nie (Zahr en Balian, 1995: 180).

Al hierdie faktore het tot gevolg dat die premature baba dikwels geïrriteerd voorkom, negatief reageer op behandeling of nie na wense vorder nie. Konstante hantering en intervensie van siek premature babas mag hul risiko vir mediese komplikasies verhoog en ontwikkeling vertraag (Zahr en Balian, 1995:184).

'n Moontlike manier om hierdie negatiewe stimuli uit te skakel is deur musiek aan die premature baba te speel. Musiek kan in die agtergrond gespeel word, maar beter resultate word verkry wanneer daar konstruktief na die musiek geluister word (Hughes en Birkheid, 1993:6). Die musiek moet aan die volgende vereistes voldoen: dit moet stadige, eweredige, gestruktureerde, nie-emosionele musiek wees met ' $n$ lae volume. Daar is heelwat musiek wat aan hierdie kriteria voldoen, maar daar is gevind dat die beste resultate verkry word deur stadige musiek uit die Barokera (Hughes en Birkheid, 1993: 6).

\section{DIE INVLOED VAN RUSTIGE MUSIEK OP BABAS}

Die menslike liggaam bevat al drie die basiese elemente wat in musiek gevind word, naamlik klank, slagmaat en ritme. Wanneer musiek gespeel word, resoneer die liggaam saam met die musiek (Grové, 1991: 113).

Uit Caine (1991:190) se navorsing waar musiek aan premature babas gespeel is, is die volgende resultate gevind:

* Daar was ' $n$ groter kalorie inname deur die babas wat musiekterapie ontvang het.

* Daar was minder aanvanklike gewigsverlies.

* Die babas was kalmer.

* Minder stresvolle optrede het voorgekom.

* Daar was vinniger ontslag uit die hospitaal (Caine, 1991: 190).

Musiek het ' $n$ positiewe fisiologiese, psigologiese en emosionele effek op die mens (Van Schalkwyk, 1990: 15). Musiek masseer die hele liggaam, maar hoofsaaklik die limbiese sisteem van die brein en dit beïnvloed weer die outonome funksies van die liggaam. So varieer die harttempo, asemhalingstempo en bloeddruk na aanleiding van die musiek waarna daar geluister word (Hughes en Birkheid, 1993: 5).

Musiek help om te ontspan, te streel en uitdrukking van die self te bevorder, dit help die pasiënt om angs, bangheid, depressie, spanning en onttrekking te verlig as hy pyn ervaar (Van Schalkwyk, 1990: 10-17).

Uit vorige navorsing is getoon dat rustigheid by ' $n$ baba slegs ' $n$ positiewe invloed op hom kan hê. Dit het dikwels gelei tot vinniger post-operatiewe herstel, vinniger ontslag en ' $n$ toename in gewig. Daar is ook gevind dat musiekterapie kan lei tot verbeterde oksigenasie (Leonard, 1993: 47-48).

Zahr et al. (1995:180) het deur navorsing getoon dat ontspanning wat teweeggebring word deur musiek, fisiologies gemeet kan word deur ' $n$ afname in harttempo, asemhalingstempo en bloeddruk. Daar is ook gevind dat musiek ' $n$ direkte effek het op gedrag (Rohnre en Miller, 1980: 2). Die respons op stimuli by die baba kan verder gemeet word deur slaap en wakker fases, huil en kleurverandering wat plaasvind (Zahr en Balian, 1995:180).

\section{DIE INVLOED VAN STADIGE BAROKMLSIEK OP DIE MENS}

Barokmusiek het ' $n$ positiewe effek op volwassenes en kinders, maar die effek op premature babas is nog net beperk ondersoek. Barokmusiek is daarvoor bekend dat dit positief op die menslike liggaam inwerk, 'n 
ontspannende gemoedstoestand en gevolglik ' $n$ ontspannende en rustige liggaam tot gevolg het. Selfs breingolwe skakel in by Barokmusiek en die stadige en rustige patroonmatige gang van die musiek (Grové, 1991:113 ). Shani Grové verwys daarna as helende of harmoniserende musiek (Grové, 1991: 113).

Breingolwe verander na alfaritme wanneer daar na stadige barokmusiek geluister word. Alfaritme reflekteer ' $n$ ontspanne gemoedstoestand, maar terselfdertyd ' $n$ verhoogde bewussyn en ' $n$ verskerping van breinfunksies. Wanneer die breinfunksies in alfa ritme is, funksioneer jy beter (Grové, 1991: 113).

Die breinstam of die primitiewe brein kontroleer die hartempo, asemhalingstempo en spierspanning van die mens (Van Schalkwyk, 1990: 15). Alfabreingolwe bring ' $n$ ontspanne, verskerptheid wat spanning en angs domineer (Van Schalkwyk, 1990: 18).

Wanneer ' $n$ mens na barokmusiek luister, toon dele van die brein wat nie andersins benut word nie, dat dit ook gestimuleer word en dus gebruik word. Gevolglik het hierdie musiek 'n direkte uitwerking op die brein (Grové, 1991: 122). Die musiek moet minstens tien minute lank gespeel word (Hughes en Birkheid, 1993: 6).

Dit is belangrik om slegs na die stadige gedeeltes van barokmusiek te luister. Die stadige bewegings van barokmusiek het ongeveer een slagmaat per sekonde en die tempo word dikwels as largo aangedui (Hughes en Birkheid, 1993: 6).

\section{NAVORSINGSONTWERP}

In die studie word 'n kwalitatiewe ontwerp gebruik. Deur middel van gevallestudies, word die effek van stadige barokmusiek op premature babas verken en beskryf. Die ingesamelde data waar geen musiek gespeel is nie en waar barokmusiek.wel aan premature babas gespeel is sal daarna vergelyk word. Die ontwerp kom voor binne die konteks van twee privaat hospitale in Pretoria.

\section{STEEKPROEF}

Vyf premature babas is as voorstudie gebruik om te bestudeer of stadige barokmusiek "n positiewe effek op hulle gedrag toon en hoe lank dit neem voordat die premature babas se bewegings verminder.

'n Verdere tien premature babas is op grond van die voorstudie in die studie ingesluit en ' $n$ volledige gevallestudie is op elkeen van hulle gedoen.

Die babas moes aan die volgende kriteria voldoen om in die steekproef ingesluit te word:

* Die baba moes prematuur gewees het. (minder as 37 weke gestasie)

* Die baba moes nie gesedeer wees nie.

* Die baba moes nie bloeddruk- of hartmedikasie ontvang het nie.
* Die baba moes nie medikasie ontvang het wat gehoorskade kan veroorsaak nie.

* Die baba moes minder as tien dae oud wees

* Die baba moes meganies geventileer wees.

\section{NAVORSINGSMETODE}

Die tien babas is afsonderlik oor ' $n$ tydperk van ongeveer ses ure geobserveer. Die observasie is in vier fases verdeel.

\section{Fase 1}

\section{Sonder musiek}

Die baba is ' $n$ halfuur lank voor hantering bestudeer. Deur middel van veldnotas is beskryf hoe die baba op sy omgewing reageer. Kwantitatiewe data is gebruik om die baba se reaksie te meet. Elke minuut is die baba se harttempo, saturasie en asemhalingstempo aangeteken soos gevind op die gekoppelde monitors. Die monitors wat gebruik is was die $S \& W$ Neoscope en die Vickers Saturasie monitor. Elke vyf minute is die baba se bloeddruk vanaf die gekoppelde bloeddrukapparaat aangeteken. Die Vickers Saturasie monitor is hiervoor gebruik. Deurlopende bewegings is op die veldnotas aangebring. Hantering het geskied direk nadat die baba vir die halfuur geobserveer is. Met hantering word die fisiese aktiwiteite bedoel wat nodig is om lewensredding uit te voer en gemak te verseker, byvoorbeeld endotrageale intubasies, inplasing van infuuslyne, suiging van lugweë, voeding, ruil van doeke en neem van vitale data.

\section{Fase 2}

\section{Sonder musiek}

Direk na hantering is die baba weer vir ' $n$ halfuur geobserveer en is dieselfde kriteria gebruik om die premature baba se gedrag te beskryf. Ongeveer twee ure het verloop voor die aanvang van die volgende fase.

\section{Fase 3}

\section{Met barokmusiek}

$\mathrm{Vir}$ ' $\mathrm{n}$ halfuur voor die volgende hantering is daar stadige barokmusiek aan dieselfde premature baba gespeel. Oorfone is op die baba se ore geplaas om eksterne geluide so ver moontlik uit te doof. Die musiek is teen $58 \pm 2$ $\mathrm{dB}$ aan die babas gespeel. Bogenoemde kriteria is weer vir observasie gebruik. Die barokmusiek is daarna verwyder en hantering het direk daarna geskied.

\begin{tabular}{|c|c|c|c|c|c|}
\hline Tydperk & $\mathbf{N}$ & $\mathbf{X}_{\mathbf{1}}$ & $X_{2}$ & T-telling & DF \\
\hline Voor hantering & 10 & 146 & 142 & 0,799786 & 18 \\
\hline $\mathrm{Na}$ hantering & 10 & 145 & 143 & 0.453896 & 18 \\
\hline \multicolumn{6}{|c|}{$\begin{array}{l}\text { Sleutels vir Tabel } 1 \text { - } 5 \\
N=\text { aantal gevalle } \\
X_{1}=\text { rekenkundige gemiddeld sonder musiek } \\
X_{2}=\text { rekenkundige gemiddeld met barokmusiek } \\
\text { DF = grade van vryheid }\end{array}$} \\
\hline
\end{tabular}

Fase 4

Met barokmusiek

Direk na hantering is die oorfone weer op die baba se ore geplaas en is barokmusiek vir ' $n$ halfuur aan die baba gespeel. Dieselfde kriteria is vir observasie gebruik. Na die halfuur is die barokmusiek verwyder. Elke baba is slegs een maal in die studie gebruik.

\section{RESULTATE UIT DIE VOORSTUDIE}

Al vyf babas wat in voorstudie gebruik is, het rustiger voorgekom terwyl stadige barokmusiek aan hulle gespeel is. Minder motoriese bewegings van die koppie, ledemate en lyfie is waargeneem. Indien die baba aan die begin van observasie gehuil het, het die huil bedaar toe die barokmusiek gespeel is.

Dit het ' $n$ gemiddelde tydperk van tien minute geneem vir die babas om rustiger te word. Uit navorsing deur Hughes en Birkheid (1993: 6) is daar voorgestel, dat musiek minstens tien minute gespeel moet word, voordat ' $n$ reaksie opgemerk word. Die voorstudie wat gedoen is, bevestig die navorsing deur Hughes en Birkheid (1993: 6).

\section{RESULTATE UIT DIE GEVALLESTUDIES}

Die resultate word weergegee in tabelle en grafieke wat gevolg word deur ' $n$ kort bespreking.

\section{Die gemiddelde harttempo van die tien premature babas}

In Tabel 1 volg ' $n$ uiteensetting van die resultate van die gemiddelde harttempo van die babas voor en na hantering.

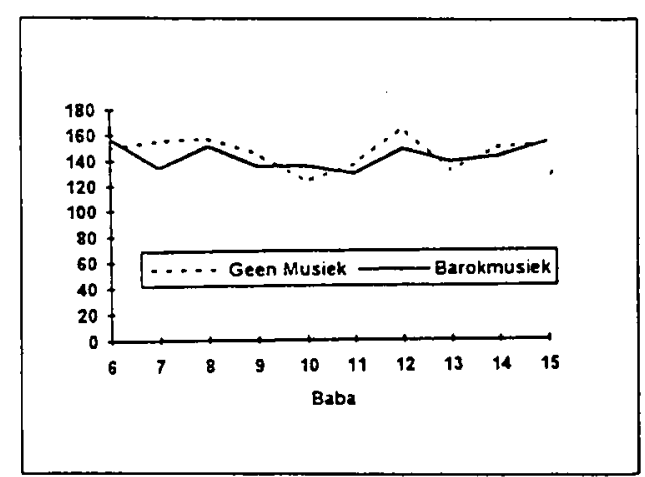

Figuur 1: Gemiddelde harttempo van die babas voor hantering 


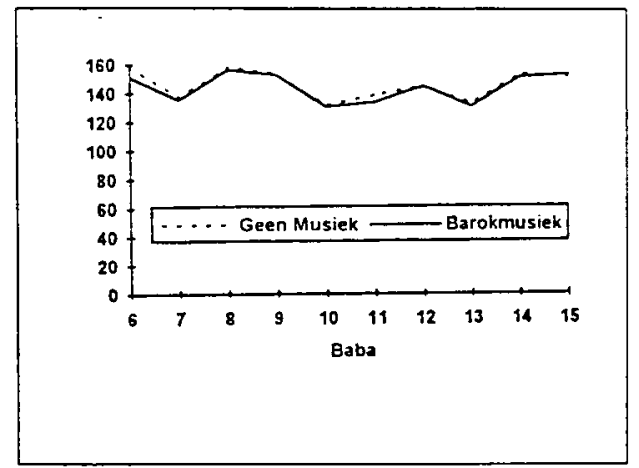

Figuur 2: Gemiddelde harttempo van die babas na hantering

Die gemiddelde harttempo van die tien babas voor hantering, was met vier slae/minuut stadiger, terwyl die barokmusiek gespeel het. Na hantering was die gemiddelde harttempo van die tien babas met twee slae/minuut stadiger met die barokmusiek as daarsonder. Dit wil voorkom asof die barokmusiek ' $n$ effense positiewe effek op die harttempo van die babas gehad het. Volgens die T-toets blyk dit egter dat op beide die $1 \%$ - en $5 \%$ - betekenispyl daar geen beduidende verskille is nie.

Die gemiddelde asemhalingstempo van die tien babas

In Tabel 2 volg ' $n$ uiteensetting van die resultate van die gemiddelde asemhalingstempo van die babas voor en na hantering.

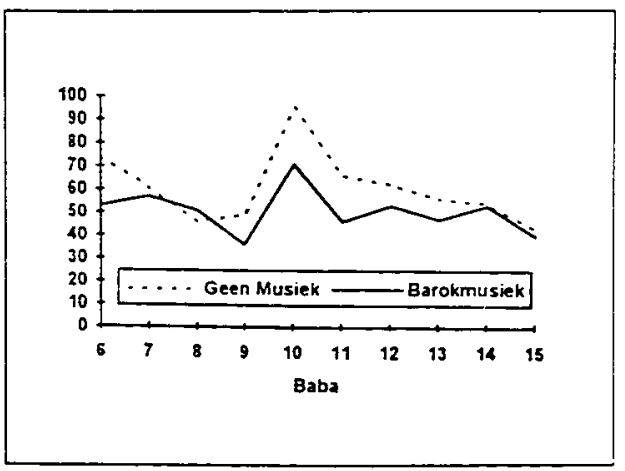

Figuur 3: Gemiddelde asemhalingstempo van die babas voor bantering

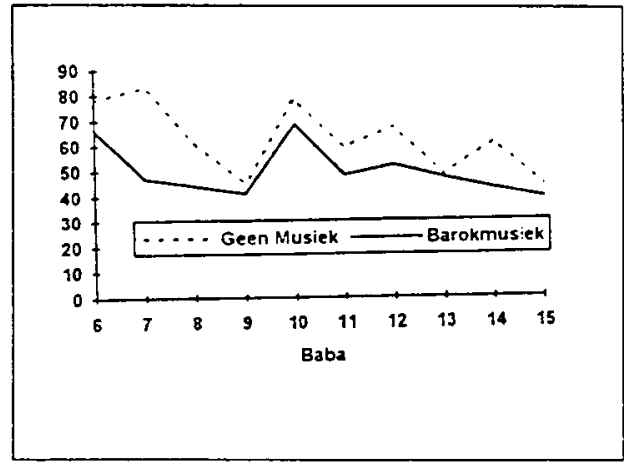

Figuur 4: Gemiddelde asemhalingstempo van die babas na hantering

Die gemiddelde asemhalingstempo van die babas voor hantering was twaalf asemhalings/ minuut stadiger terwyl die barokmusiek gespeel het as daarsonder. $\mathrm{Na}$ hantering was die gemiddelde asemhalingstempo tien asemhalings/minuut stadiger met die barokmusiek. Dit wil voorkom asof die barokmusiek voor en na hantering 'n positiewe effek op die asemhalingstempo van die babas gehad het. Volgens die T-toets blyk dit dat op beide die $1 \%$ - en $5 \%$ - betekenispyl daar beduidende verskille is.

Die gemiddelde saturasie van die tien babas

In Tabel 3 volg ' $n$ uiteensetting van die resultate van die gemiddelde saturasie van die babas voor en na hantering.

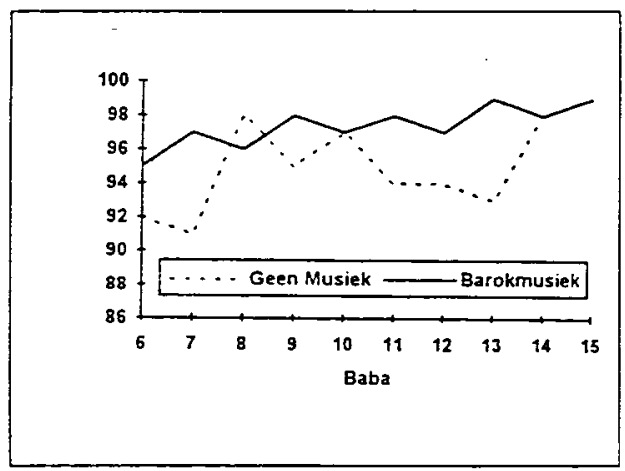

Figuur 5: Gemiddelde saturasie van die babas voor hantering

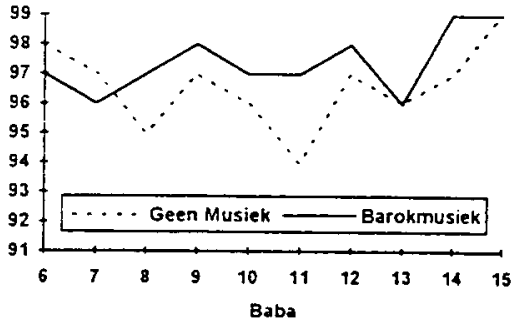

Figuur 6: Gemiddelde saturasie van die babas na hantering

Die gemiddelde saturasie van die babas voor hantering was met $2 \%$ hoër terwyl die barokmusiek gespeel het. Na hantering was die babas se gemiddelde saturasie met en sonder barokmusiek dieselfde. Dit wil voorkom asof die barokmusiek voor hantering ' $n$ effense positiewe effek op die saturasie van die babas gehad het, maar geen verskil is na hantering opgemerk nie. Uit die t-toets blyk dit dat op beide die $1 \%$-en $5 \%$-betekenispyl, daar geen beduidende verskille is nie.

Die gemiddelde bloeddruk van die tien premature babas

In Tabel 4 volg ' $n$ uiteensetting van die resultate van die gemiddelde sistoliese bloeddruk van die babas voor en na hantering.

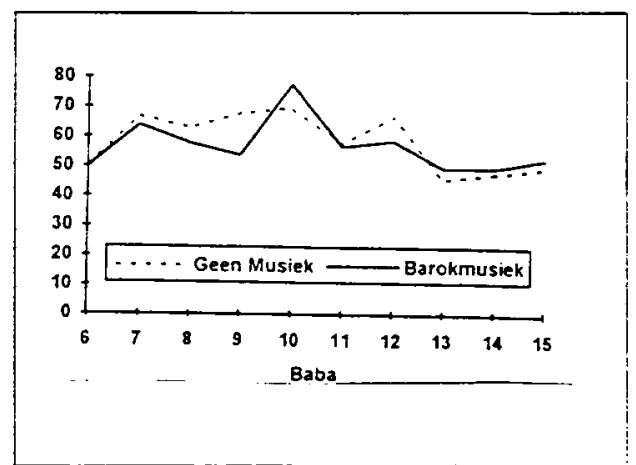

Figuur 7: Gemiddelde sistoliese bloeddruk van die babas voor bantering

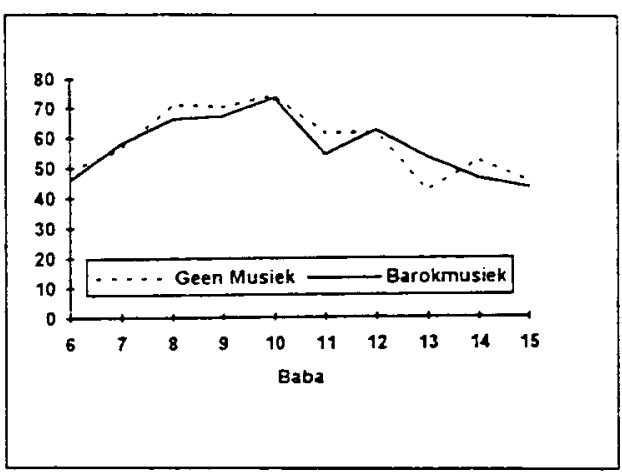

Figuur 8: Gemiddelde diastoliese bloeddruk van die babas na hantering

Die gemiddelde sistoliese bloeddruk voor hantering was met $2 \mathrm{mmHg}$ laer terwyl die barokmusiek gespeel het. $\mathrm{Na}$ hantering was die 
Tabel 5: Resultate van die gemiddelde diastoliese bloeddruk van die babas

$\begin{array}{llllll}\text { Tydperk } & N & X 1 & X 2 & \text { T-telling } & \text { DF } \\ \text { Voor hantering } & 10 & 31 & 35 & -0,10524 & 18 \\ \text { Na hantering } & 10 & 36 & 35 & 0,553795 & 18\end{array}$

gemiddelde sistoliese bloeddruk met $1 \mathrm{mmHg}$ laer terwyl die musiek gespeel het as sonder die musiek. Dit wil voorkom asof die barokmusiek ' $n$ effense positiewe effek gehad het op die sistoliese bloeddruk van die babas wat by die studie betrek is. Volgens die T-toets blyk dit dat op beide die $1 \%$ - en $5 \%$-betekenispyl, daar geen beduidende verskille is nie.

In Tabel 5 volg ' $n$ uiteensetting van die resultate van die gemiddelde diastoliese bloeddruk van die babas voor en na hantering.

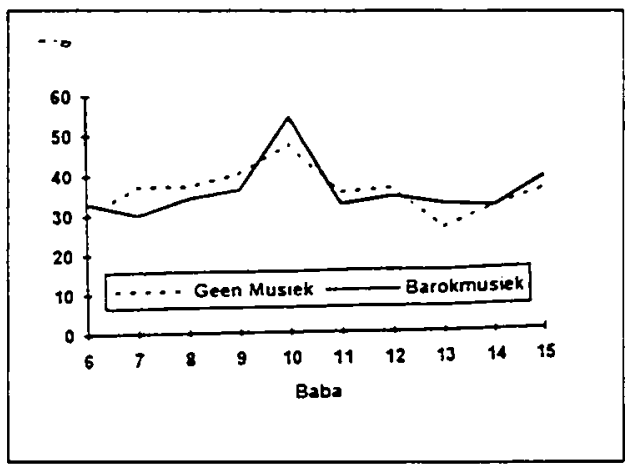

Figuur 9: Gemiddelde diastoliese bloeddruk van die babas voor hantering

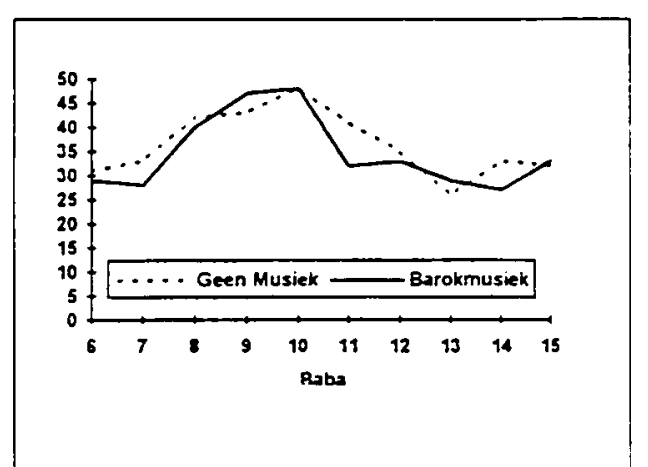

Figuur 10: Gemiddelde diastoliese bloeddruk van die babas na hantering

Die gemiddelde diastoliese bloeddruk, voor hantering was $4 \mathrm{mmHg}$ hoër terwyl die barokmusiek gespeel het. Na hantering was die gemiddelde diastoliese bloeddruk was $1 \mathrm{mmHg}$ laer terwyl die barokmusiek gespeel het. Volgens die T-toets blyk dit dat op beide die $1 \%$ - en 5\% - betekenispyl, daar geen beduidende verskille is nie.

\section{Motoriese bewegings}

Sonder musiek: Bewegings van die ogies, mondjie en koppie het by die babas voorgekom, asook rustelose bewegings van die ledemate en lyfie by sommige babas. Sommige babas het gehuil en geskrik vir geluide in die neonatale intensiewesorgeenheid.
Met barokmusiek: Bewegings van die ogies, mondjie en koppie het ook voorgekom terwyl barokmusiek aan die babas gespeel is. Soms het beweging van die ledemate en lyfie voorgekom, maar die babas het nooit geïrriteerd of rusteloos voorgekom nie. Die babas het heelwat minder gehuil en geskrik terwyl barokmusiek aan hulle gespeel is as sonder die musiek.

\section{OPSOMMING EN AANBEVELINGS}

Die data wat verkry is, het getoon dat die grootste effek verkry is waar barokmusiek voor hantering aan die babas gespeel is. Dit mag wees omdat eksterne faktore voor hantering ' $n$ rol speel, byvoorbeeld ongemak weens sekresies in die lugweë, honger of ' $n$ nat doek. Hierdie eksterne faktore mag moontlik bydra tot verhoogde geïrriteerdheid en rusteloosheid by premature babas. Barokmusiek neem nie hierdie eksterne faktore weg nie, maar fokus die babas se aandag op aangenamer dinge. Deur dit te doen, is die babas minder bewus van hulle omgewing en kan hulle konsentreer op iets wat positief op hulle inwerk.

Samevaltend kan daar gesê word dat die asemhalingstempo volgens die t-toets ' $n$ beduidende verskil getoon het terwyl stadige barokmusiek gespeel is. Die babas het ook minder geïrriteerd en huilerig voorgekom toe musiek gespeel is. Volgens die T-toets het geen beduidende verskille by die harttempo, saturasie en bloeddruk van die babas voorgekom terwyl die barokmusiek gespeel is nie.

Daar word aanbeveel dat ' $n$ groter steekproef by verdere navorsing op hierdie gebied gebruik word en dat die musiek langer aan die babas gespeel word. Ander moontlike kriteria wat ondersoek kan word is voedselabsorpsie, gewigstoename en duur van hospitalisasie.

\section{SLOT}

Die doel van die studie was om te beskryf wat die effek van stadige barokmusiek op die harttempo, asemhalingstempo, saturasie, bloeddruk en motoriese bewegings van premature babas is en om riglyne daar te stel waarvolgens barokmusiek aan premature babas gespeel kan word.

Sommige babas het ' $n$ definitiewe reaksie op die stadige barokmusiek getoon, veral voor hantering, terwyl ander babas slegs ' $n$ geringe reaksie getoon het. Sommige babas het baat gevind by die musiek. Daar was egter ook babas wat geen reaksie getoon het nie. Elke baba moet individueel geëvalueer en beraam word, omdat elkeen uniek is.

\section{VERWYSINGS}

Ayllon, T \& Freed, M (1989): Stopping baby's colic: The new program designed to relieve most infants' persistent crying in 3-7 days. New York: Putmans Publising Group

Caine, J (1991): The Effects of Music on the Selected Stress Behaviors, Weight, Caloric and Formula Intake, and Length of Hospital Stay of Premature and Low Birth Weight Neonates in a Newborn Intensive Care Unit. Jeumal of Music Therapy, 28(4), 180-192

Collins, SK (1991): Music Therapy in the Neonatal Intensive Care Unit. Neonatal Network, 9(6), 23-26

De Lue, NA (1976): Climate and Environmental Concepts. Clinical Perinatology, 3(2), 425-430

Grové, S (1991): Dankie, Brein. Kaapstad: Human \& Rousseau

Hughes, J \& Birkheid, S (1993): Stress relief through music. South African Joumal of Music Therapy, 10(3), July 1992: 3-7

Keet, MP; Harrison, VC \& Shore, SCL (1987): Die pasgebore baba. Kaapstad: Juta.

Leonard, JE (1993): Music Therapy: Fertile Ground for Application of Reasearch in Practice. Neonatal Network, 12(2), 47-48

Mills, L \& Aikin, AK (1984): Neonatology: Technology of the future. Neonatal Nerwork. 3 August 1984: 34-39

Rohner, SJ \& Miller, R (1980): Degrees of familiar and affective music and their effects on state anxiety. loumal of Music Therapy, 17(1), 2-15

Shogan, MG \& Schumann, LL (1993): The Effect of Environmental Lighting on the Oxygen Saturation of Preterm Infants in the NICU. Neonatal Network 12(5), 7-13

Thomas, KA (1989): How the NICU sounds to a Preterm Infant. American Joumal of Matemal \& Child Nursing, 14(4), 249-251

Van Schalkwyk, G (1990): Music for pain relief and stress management. South African_Joumal of Music Therapy, 8(3), 1418

Weibly, TT (1989): Inside the Incubator. American Joumal of Matemal and Child Nursing, 14(2), March/April 1989: 96-100

Woodward, SC; Guidozxi, F; Hofmeyr, GJ; De Jong, P; Anthony, J \& Woods, D (1993): Indications for the therapeutic use of music in the pre-, peri- and postnatal periods. South African Joumal of Music Therapy, 10(3), Jnly 1992: 14-19

Zahr, LK \& Balian, S (1995): Responses of Premature Infants to Routine Nursing Interventions and Noise in the NICU. Nursing Research, 44(3), 179-185

Ziporyn, T (1984): Music Therapy accompanies medical care. IAMA, 252(8), 986-987

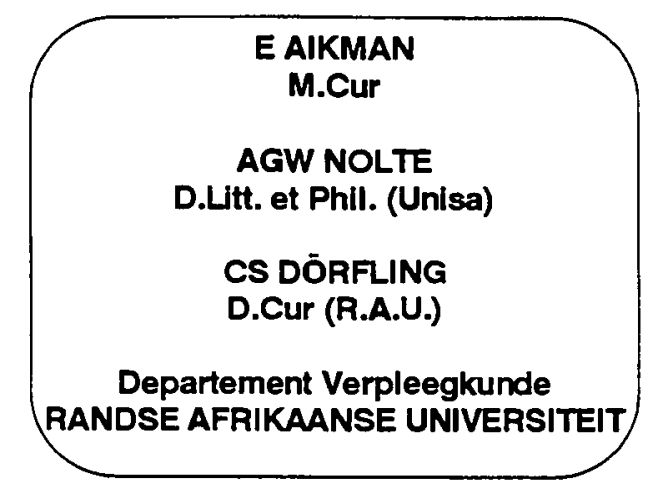

